DOI: $10.14451 / 2.125 .47$

\title{
ИНТЕГРАЦИЯ ОСНОВНЫХ ИМПОРТОЗАМЕЩАЮЩИХ ОТРАСЛЕЙ В ЭКОНОМИКУ РЕГИОНОВ: ПРОБЛЕМЫ И ВОЗМОЖНОСТИ "
}

\author{
(c) 2018 Исаева Елена Владимировна \\ начальник Центра управленческих компетенций \\ Омский государственный технический университет \\ 644050, Омск, пр. Мира, д. 11 \\ E-mail: ev_isaeva@mail.ru
}

В статье поднимается проблема снижения динамики импортозамещения по основным отраслям экономики России. Как одна из причин этого, по мнению автора, произошедшие за последние годы слияния и поглощения средних и малых региональных предприятий крупными федеральными и международными холдингами. В этой связи предлагается сделать акцент на инициацию проектов по импортозамещению именно среди средних региональных предприятий, которые, с одной стороны, сохранили свою самостоятельность и в связи с этим более гибки в инициации новых проектов и скорости принятия решений по ним. С другой, они обладают некоторыми ресурсами и имеют конкурентные преимущества (относительно низкие заработные платы, стоимость ключевых ресурсов - земля, недвижимость и пр.). В совокупности эти условия, вместе с грамотным исследованием внешних рынков и качественной экспертной оценкой, способны сделать эти проекты вполне конкурентоспособными на больших рынках. При этом, данные проекты будут являться и привлекательными для территории, поскольку будут вовлекать в оборот свободные ресурсы и какой-то степени способствовать развитию регионов. В качестве инструмента оценки региональных проектов в направлении импортозамещения, автор предлагает использовать матрицу «привлекательностьконкурентоспособность», которая строится на основании экспертной оценки региональных проектов по ряду критериев. В результате матрица оценки проектов дает ясное понимание, в какую группу попадает тот или иной проект и представлены рекомендации по каждой группе.

Ключевые слова: импортозамещение, региональные проекты, привлекательность и конкурентоспособность проектов, оценка проектов.

Сохранение динамики развития внутреннего производства в Российской Федерации на фоне нестабильной экономической ситуации на мировых рынках и пока слабых темпов посткризисного восстановления российской экономики, требует более скоординированного подхода к внедрению программ импортозамещения в разных отраслях.

Анализируя предыдущий опыт развития импортозамещения в российской промышленности, можно выделить два относительно самостоятельных этапа в этом направлении:

1 этап (2008-2014 гг.) - первая волна импортозамещения, которая характеризовалась относительно быстрым «включением» отраслей с коротким жизненным циклом и высокой скоростью оборота вложенных инвестиций (сельское хозяйство, перерабатывающая промышленность и т.п.). В это время предпринимательский сектор и крупные корпорации включились в программу без активного «влияния» со стороны государства, поскольку была опора в основном на внутренний спрос, и его было достаточно для обеспечения возврата вложенных инвестиций в среднесрочном или краткосрочном периоде. Более того, это был период, когда экономика страны (в т.ч. потребительский её сектор) активно кредитовались банковским сектором, что также позволяло поддерживать высокий уровень покупательской активности. Поэтому на первой волне проекты по импортозамещения обеспечивали хороший прирост в отраслях (до 10\% в год).

2 этап (2014-2017 гг.) - вторая волна импортозамещения. В этот период государство активно включает протекционистские меры, связанные не только с приоритетом при закупках отечественных и импортных аналогов продукции и технологий, но и водит прямые запреты на использований импортной продукции и технологий в целом ряде отраслей. Сначала это касается предприятий оборонно-промышленного комплекса и других стратегически значимых

\footnotetext{
* Исследование выполнено при финансовой поддержки РФФИ, проект № 17-32-00037
} 
отраслей (что вполне логично), позже распространяется и на другие отрасли, продукты и технологии (сельское хозяйство, приборостроение, энергетика и ТЭК, ІТ и др.).

3 этап (2018 г.) - это этап, когда предыдущие, «быстрые» эффекты импортозамещения исчерпаны. Более того. К этому этапу стало понятно, что отставание России по ряду направлений достаточно большое и не может быть ликвидировано на горизонте даже 3-5 лет. Это, прежде всего, современное машиностроение, высокотехнологичные разработки, медицина и фармацевтика и ряд других. И теперь многие предприятия, да и целые отрасли, оказались в двоякой ситуации. С одной стороны, продолжающееся санкционное давление со стороны многих зарубежных партнеров и ответственные санкции, создают «условно-долгосрочную» протекционистскую возможность для налаживания внутреннего производства аналогичных продуктов или создания технологий. С другой стороны, наши предприятия, к сожалению, мало были ориентированы в массе своей на внешние рынки (в основном, на внутренние потребности) и к снижению темпов роста российской экономики, оказались не готовы. То есть, то, что они производят, не вполне конкурентоспособно на других рынках. И это не дает возможность развернуть производство импортных аналогов продуктов и технологий в полной мере.

И эти вопросы тоже можно было бы решать, если бы ситуация не усугублялась еще и произошедшими за последнее время организационными решениями в российской промышленности. Поскольку в последние 10 лет происходило массовое поглощение региональных предприятий крупными федеральными и международными компаниями, по сути, исчезли с рынка относительно самостоятельные и мобильные промышленные предприятия в регионах, которые могли бы быстро реагировать на какие-то потребности внешних рынков и разворачивать в отдельных регионах производство новых продуктов.

Вместе с тем, по мнению автора, именно региональные предприятия, которые являются скорее средними по объему выручки и численности работников, могут стать локомотивом для инициации и разработки проектов на данном этапе. Эти предприятия могут инициировать региональные проекты по импортозамещению, которые будут способствовать не только решению этой большой проблемы, но и стиму- лировать экономическую активность во многих регионах, на не только в столичных города. Причин для этого несколько:

- гибкость и скорость в принятии решений в проекте, поскольку требуется меньше согласований в корпоративной иерархии;

- возможность привлечения партнеров (в том числе крупных) для расширения проекта в случае необходимости;

- относительно низкие издержки (прежде всего, на заработную плату;

- наличие относительно дешевых свободных ресурсов в регионах (земля, недвижимость и пр.).

Конечно, любые проекты по импортозамещению, в т.ч. региональные, требуют предварительно оценки и обсуждения для понимания какие из них предпочтительнее с точки зрения отдачи.

Для этого автор предлагает использовать матрицу проектов, в которой любые проекты регионов, направленные на импортозамещение, можно будет сравнивать с другими по схожим параметрам. Для построения такой матрицы первоначально необходимо выделить критерии, по которым проекты будут оцениваться и сравниваться между собой.

В качестве признаков сегментирования предлагается выделить следующие характеристики региональных проектов:

- уровень решаемой проблемы: мировой, страновый, региональный;

- направленность решаемой проблемы проекта: экономические, социальные, инновационные;

- сроки реализации проектов: до 1 года, от 1 до 5 лет, более 5 лет.

Кроме этого, любые предлагаемые проекты нужно оценивать еще и с позиции их привлекательности и конкурентоспособности (табл.).

Обозначенные критерии являются основополагающими, так как позволяют разделить проекты на принципиально отличные друг от друга сегменты. К тому же все признаки имеют однозначную интерпретацию. Несмотря на тот факт, что проекты могут решать ни одну проблему, а комплекс, у нее все равно есть основная цель и направленность.

Следует отметить, что автор не включил в рассмотрение критерий бюджет проектов, так как это не столько критерий сегментирования, сколько ограничение, которое действует при вы- 
Таблица. Первоначальные критерии оценки привлекательности и конкурентоспособности региональных проектов

\begin{tabular}{|c|c|}
\hline Частный показатель & Критерии оценки частных показателей \\
\hline \multicolumn{2}{|c|}{ Привлекательность проекта } \\
\hline 1. Значимость проекта & $\begin{array}{l}\text { 1.1. Бюджетно-экономическая значимость проекта } \\
\text { 1.2. Стратегическая и социальная значимость проекта }\end{array}$ \\
\hline 2. Результативность проекта & $\begin{array}{l}\text { 2.1. Доля индикаторов и показателей от общего количества } \\
\text { индикаторов и показателей развития территории, которые } \\
\text { планируется улучшить } \\
\text { 2.2. Характер влияния проекта на реализацию других проек- } \\
\text { тов территории /государства }\end{array}$ \\
\hline \multicolumn{2}{|c|}{ Показатели конкурентоспособности проекта } \\
\hline 1. Востребованность проекта & $\begin{array}{l}\text { 1.1. Согласованность целей и задач проекта с приоритетны- } \\
\text { ми направлениями развития государства/территории } \\
\text { 1.2. Характер решаемой проблемы проектом } \\
\text { 1.3. Соответствие проекта организационным возможностям } \\
\text { его участников }\end{array}$ \\
\hline 2. Степень проработанности проекта & $\begin{array}{l}\text { 2.1. Логичность структуры проекта } \\
\text { 2.2. Обоснованность предложенных мероприятий проекта } \\
\text { 2.3. Опыт реализации подобных проектов }\end{array}$ \\
\hline 3. Общественная экспертиза проектов & $\begin{array}{l}\text { 3.1. Востребованность проекта в потребительском секторе } \\
\text { внутри страны или других стран } \\
\text { 3.2. Востребованность проекта в бизнес секторе нашей стра- } \\
\text { ны или других стран }\end{array}$ \\
\hline
\end{tabular}

боре проектов, в том числе с учетом возможностей и источников его финансирования. Он должен учитываться позднее - при формировании работы с портфелем проектов.

Используя метод экспертной оценки, можно все проекты, которые предлагаются в регионах, можно расположить в матрице (рисунок) для обеспечения адекватного сравнения и оценки проектов между собой.

Таким образом, в результате сегментирования были выделены восемнадцать однородных сегментов проектов, возможных для сравнения и выявления лучших среди них для формирова- ния «продуктового портфеля» региона и наглядного понимания ключевых направлений участия его в федеральной программе по развитию внутреннего производства. Данные сегменты ниже представлены в виде трех укрупненных групп:

1. «Зеленая» (верхняя) группа - проекты, которые обладают высокими экспертными оценками и по привлекательности для региона и по конкурентоспособности на уровне страны/мира. При наличии надежных и стабильных источников финансирования, эти проекты всегда являются приоритетными. Если при анализе

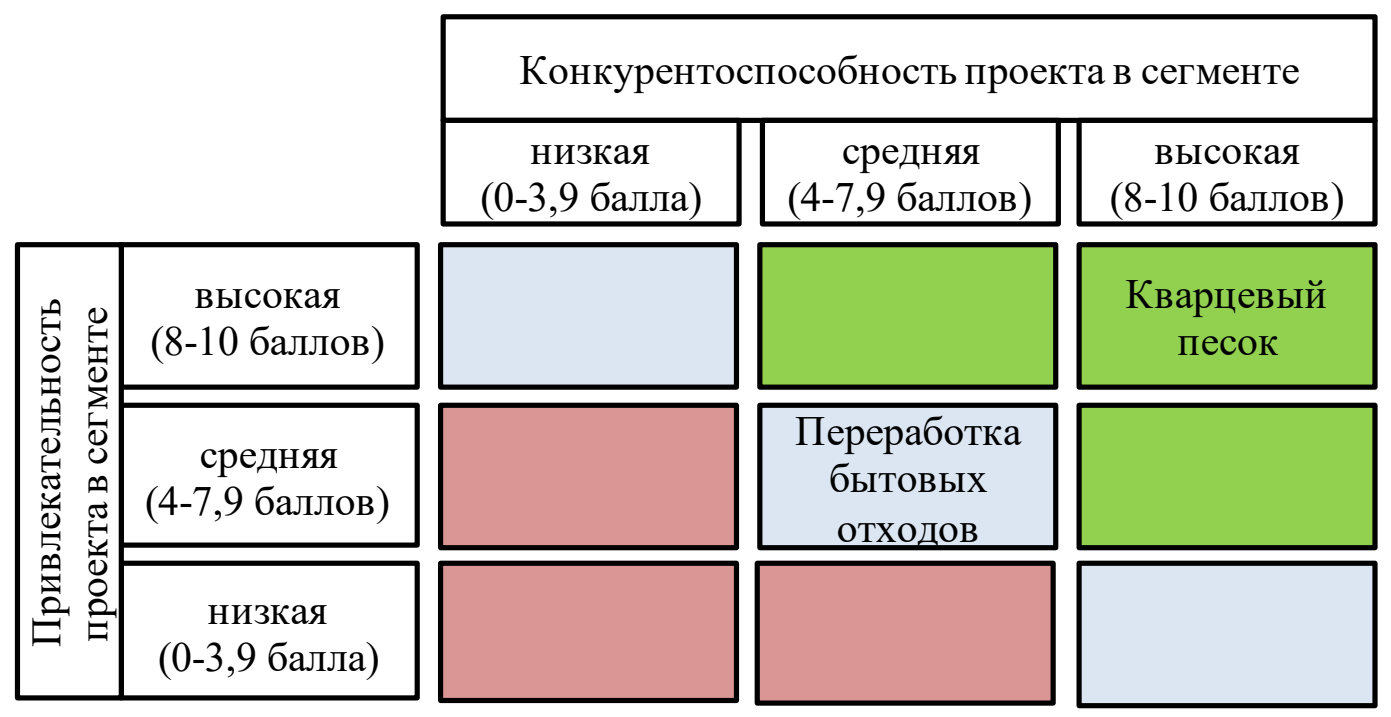

Рис. Матрица «привлекательность - конкурентоспособность» для определенного сегмента проектов 
в этой группе проектов нет, нужно их инициировать, прежде всего, с позиции конкурентоспособности.

2. «Серебряная» (средняя) группа - проекты, которые находятся в среднем диапазоне по заданным критериям. По ним нужно максимально поработать по критерию конкурентоспособности и оценить возможность перехода в верхнюю группу. В текущем состоянии эти проекты можно реализовывать, если есть инвестиционные ограничения.

3. «Розовая» (нижняя) группа - проекты скорее привлекательные для территории, и кон- курентоспособные на уровне отдельных регионов. И они могут обеспечить слабый эффект импортозамещения на уровне страны или отрасли.

C учетом вышеизложенного, на современном этапе развития экономики России, интеграция регионов в программу импортозамещения в отдельных отраслях возможна через инициацию и развития проектов самостоятельных региональных предприятий. В силу отмеченных выше особенностей, именно проекты предприятий в регионах, способны улучшить динамику развития отдельных отраслей в Российской Федерации.

\section{Библиографический список}

1. Беспалов Н. Импортозамещение и локализационные процессы в России по итогам 2016 года //Ремедиум. Журнал о российском рынке лекарств и медицинской технике. 2017. № S13. С. 154-159.

2. Науменко С.М., Шевцова О.Н., Волкова С.В., Селина Д.М. Импортозамещение как инструмент регулирования экономики //Университетская наука. 2017. № 2 (4). С. 80-83.

3. Слатвицкая И.И., Матюшенко Н.А. Импортозамещение как ключевой фактор стабилизации экономики России в условиях экономических санкций //Научная гипотеза. 2017. № 4. С. 51-57.

4. Клевцов О.И., Башарина А.С., Павлова Д. С., Якунина К.Д. Импортозамещение и стратегическое планирование развития территорий в условиях санкций и глобализации национальной экономики в рамках ЕАЭС // Аллея науки. 2018. Т. 1. № 4 (20). С. 814-817.

5. Гнидченко А.А. Импортозамещение как дополняющая стратегия //Проблемы прогнозирования. 2017. № 6 (165). C. 27-36. 